\title{
Refractory Chronic Leukemia
}

National Cancer Institute

\section{Source}

National Cancer Institute. Refractory Chronic Leukemia. NCI Thesaurus. Code C150044.

Chronic leukemia that is resistant to treatment. 